\title{
El reposicionamiento estratégico de las constructoras españolas
}

\section{The strategic repositioning of spanish construction companies}

\author{
R. Martín ${ }^{(*)}$, J. González(**)
}

\section{RESUMEN}

El presente trabajo repasa algunas de las cuestiones clave que caracterizan la industria de la construcción en España, desde el punto de vista empresarial. La transformación del sector en los últimos años ha sido la respuesta a las circunstancias y los acontecimientos del mercado, tales como el comportamiento de la demanda, los aspectos financieros o los cambios regulatorios y sus efectos sobre las compañías, que han motivado la apertura de nuevas líneas estratégicas.

La transformación de las compañías ha sido un fenómeno en cascada y ha impulsado una revolución en la industria, ha transformado productos y estrategias productivas, conduciendo, en última instancia a políticas empresariales como la diversificación, integración, internacionalización y la generalización de los contratos subordinados, lo que marcará las nuevas reglas del juego.

Por último, en base a lo anterior, se plantean las principales expectativas y algunas líneas estratégicas que definirán las actuaciones de las empresas para los próximos años, asumiendo la realidad actual de la economía y el sector. Las decisiones tomadas hoy determinarán el papel que desempeñarán durante los próximos años.

Palabras Clave: estructura de la construcción, diversificación, integración, internacionalización, subcontratación.

\begin{abstract}
SUMMARY
This paper reviews some of the key issues that characterize the construction industry in Spain, from the point of view of its companies. The transformation of this sector is the response to past events such as the behavior of demand, the financial or regulatory changes and their effects on companies and many others, which have led to new strategies.
\end{abstract}

The transformation of the companies has happened, first, in the top ranked firms, and later it has extended to the rest. It has prompted a revolution in the industry, creating new products and mechanisms, leading ultimately to business policies such as diversification, integration, internationalization and the spread of outsourcing as the new key success factors, joining this sector to an upper scope game.

Finally, based on the above, the main expectations and some lines that will define strategic business actions for the coming years are raised, assuming the current reality of the economy and industry. Present decisions will determine the future role in the coming years.

Keywords: construction industry structure, diversification, integration, internationalization, outsourcing.

\footnotetext{
${ }^{*}$ Dr. en Economía Financiera. Profesor Dpto. de Economía de la Empresa. Facultad de CC. Económicas y Empresariales-UNED. Madrid (España)

${ }^{(*)}$ Máster MBA Executive por ICADE. Profesor Dpto. de Economía de la Empresa. Facultad de CC. Económicas y Empresariales-UNED. Madrid (España)

Persona de contacto/Corresponding author: rmarting@cee.uned.es (R. Martín)
}

Fecha de recepción: 03-11-09

Fecha de aceptación: 02-02-10 


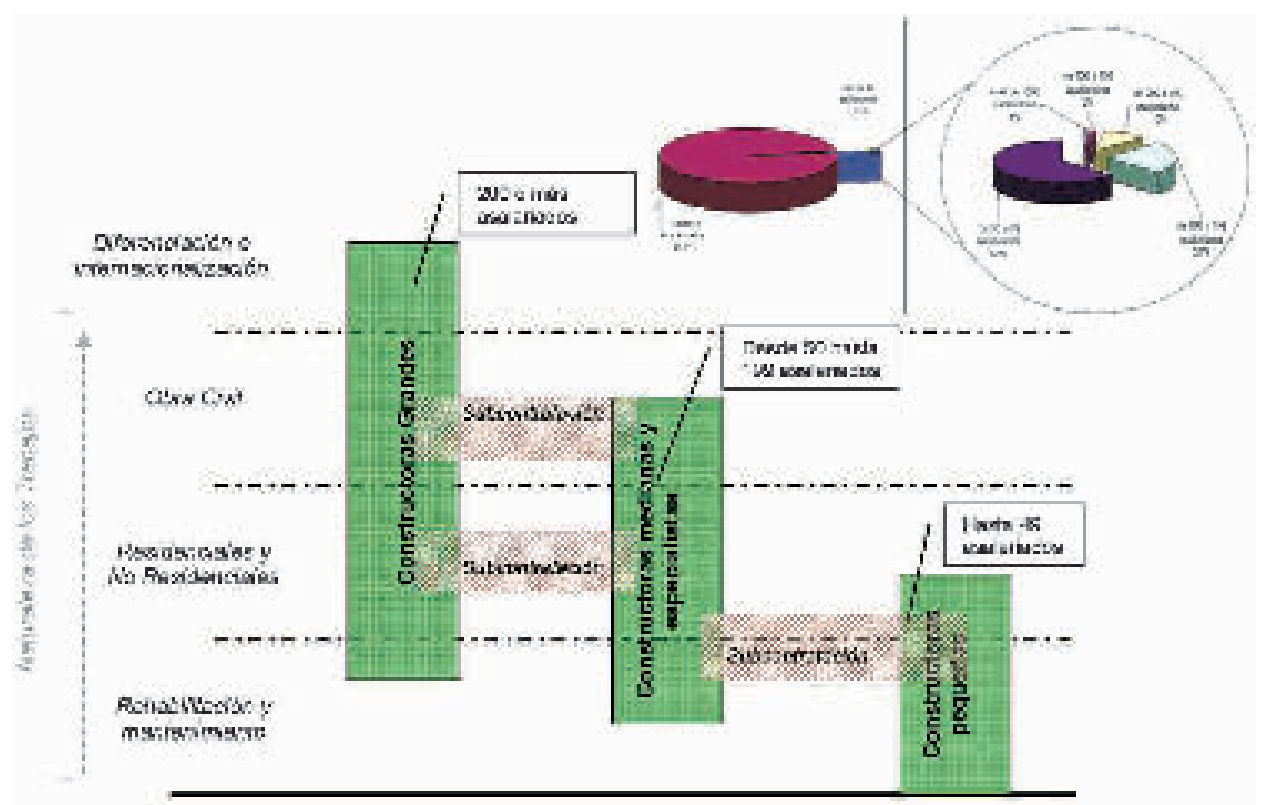

Fuente: Elaboración propia.

\section{INTRODUCCIÓN}

La construcción, sector clave en el modelo económico español, se lleva a cabo por un gran número de empresas de todos los tamaños, con acusadas diferencias atendiendo a su objeto social. Las pequeñas y medianas se dedican, con frecuencia, únicamente a la construcción, mientras que las grandes han ampliado su cartera a otras actividades, tales como la energía, industria y servicios.

Este sector tiene un comportamiento singular en el mundo empresarial, por las peculiaridades que presenta en lo relativo al producto final, al proceso de fabricación y a los agentes que intervienen, configurando un negocio caracterizado por la separación de las actividades de diseño, promoción y ejecución de las obras y por el elevado nivel de especialización de las empresas y los trabajadores.

Las empresas constructoras constituyen una población amplia y heterogénea, en la cual, en términos generales, los pequeños negocios se centran en obras de edificación, mientras que la ingeniería civil está reservada para los grandes jugadores (para las empresas de 500 o más empleados, lo que les supone el $60 \%$ de su cifra de negocio). Esta fuerte especialización por grupos no excluye la presencia de especialistas (por ejemplo, pequeñas empresas dedicadas a redes de saneamiento y drenaje, rellenos hidráulicos y mantenimiento de carreteras, excavación, rellenado y nivelación de emplazamientos, canalizaciones, redes fluviales, desecación de zonas húmedas, etc.). Además, existe un importante número de medianas compañías que se dedican a la ingeniería -responsables del aumento de la actividad de obra civil que se viene produciendo en el segmento de las constructoras medianas-y algunas constructoras grandes especializadas en construcción residencial (véase figura 1).

Desde comienzos de la década de los 90, la estructura de la industria ha experimentado una fuerte transformación. Las empresas que entran en la segunda década del siglo $\mathrm{XXI}$ poco tienen que ver con las existentes 20 años atrás y han llegado a esta situación como consecuencia de un cúmulo de factores.

El presente trabajo analiza las circunstancias que han llevado a las constructoras a la situación actual, para ello, primeramente, se describirá qué supone la construcción en España, desde el punto de vista del sector, mostrando las cualidades distintivas frente a países del entorno y prestando atención a dos aspectos de máxima importancia: el marco normativo que afecta a la construcción y los planes de promoción directa de este tipo de inversiones. Este análisis dará paso a la descripción de la industria desde un punto de vista dinámico, enfocando el estudio en las compañías de mayor calado que son, sin duda, las que marcan la pauta estratégica del negocio, asignando el posicionamiento de cada tipo de empresa en función de sus características e historial.

En el apartado 4 analizaremos la estructura de costes del negocio, para estudiar una cuestión que determina el posicionamiento de las compañías: la subcontratación, factor que ha desencadenado la estructura actual de la industria y ha conducido a otorgar a las 


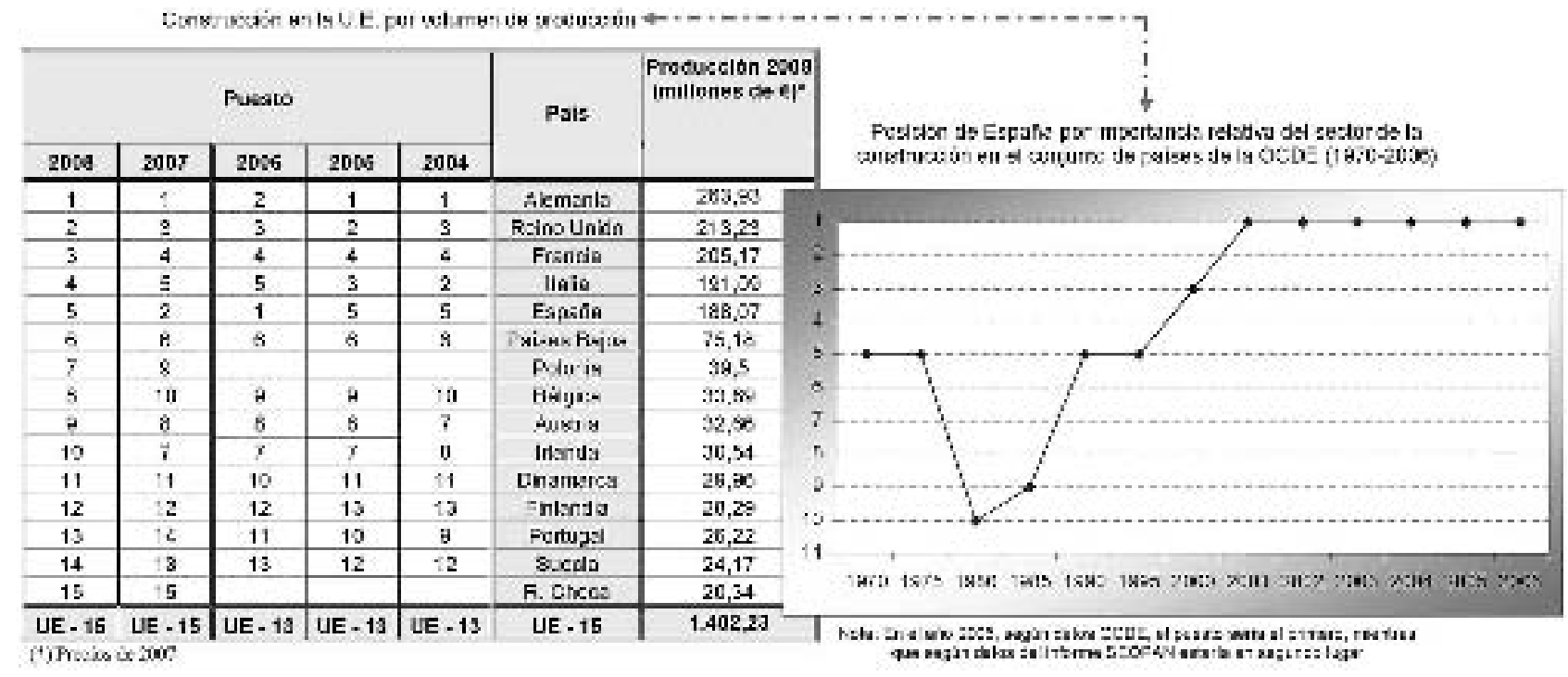

Fuente: Elaboración propia a partir de datos de SEOPAN (varios años) (1).

constructoras su papel en la producción del activo final.

Finalmente, abordaremos la motivación y dirección seguida por las empresas para incrementar la creación de valor para los accionistas cuando el negocio original no satisface sus expectativas de crecimiento: la integración vertical, la diversificación y internacionalización de la cartera. Para terminar, se mostrarán las conclusiones de los análisis realizados, se plantearán las principales expectativas de la actividad y la propuesta de líneas estratégicas para cada tipo de constructora.

\section{EL SECTOR DE LA CONSTRUCCIÓN}

Desde el punto de vista macroeconómico, la construcción tiene una gran repercusión en la economía. España destaca en la UE por la aportación del sector en términos de empleo y contribución al PIB, que ha propiciado, en los seis primeros años de esta década, un fuerte nivel de actividad, pero que implica un alto grado de dependencia de la economía con respecto a un sector que vive fuertes oscilaciones, con lo que está más expuesta a las variaciones del ciclo económico que las economías europeas con que compite (véase figura 2).

Los factores locales son, mayoritariamente, los que determinan el peso de la construcción en la economía. Tres son los países en los que el sector tiene una mayor importancia frente al resto: España, Corea del Sur y Japón.

En nuestro país, en base a las últimas cifras disponibles de Contabilidad Nacional (2008), la contribución de esta actividad suponía el 10,6\% del valor añadido bruto total, incluyendo trabajos en edificaciones y obras civiles, y empleaba al $12,5 \%$ de los trabajadores, siguiendo el informe anual de la patronal SEOPAN' 1 .

España destaca en cuanto al empleo generado por la construcción ${ }^{2}$, por el gran número de proyectos iniciados, tanto en obra civil como en edificación, y por la reducida productividad del factor trabajo en esta actividad, lo que demuestra las ineficiencias de nuestro sistema productivo, más aún cuando un trabajador de construcción en Irlanda es casi cuatro veces más productivo que uno en España ${ }^{3}$ y hay otros 11 países con una productividad aparente superior.

La primera mitad de 2008 supuso un punto de inflexión en el crecimiento del sector, experimentando desde el último trimestre de año una fuerte contracción en la actividad, en lo que supone cinco trimestres consecutivos con una tasa de variación interanual negativa cercana al $6 \%$, sin igual desde la anterior crisis del año 1992 (Contabilidad Nacional Trimestral de España, INE). Con los últimos datos disponibles al cierre de la versión definitiva de este trabajo, el número de parados del sector en marzo de 2010 superaba las 797.000 personas (Servicio Público de Empleo). Sin embargo, los datos del último mes disponible muestran cierto cambio de tendencia ya que, en el cuatrimestre anterior, el número de desempleados del sector se incrementó en cerca de 82.000 personas $^{4}$. Por otro lado, se espera una importante repercusión en la población empresarial. En 2009 ya mostraba un fuerte recorte del $40 \%$ en el número de altas de empresas, desde el máximo de 2007. Las bajas aumentaron, en el mismo período, un $74 \%$ con respecto al año anterior, como puede observarse en
2. La construcción en la Unión Europea y puesto relativo al nivel de producción y porcentaje sobre el PIB.

SEOPAN, informe anual 2008 págs. 63 y ss. (1).

2 Según la OCDE, somos el país en el que la construcción aporta un mayor valor añadido en términos porcentuales, cercano al $11 \%$ de toda la economía, además de uno de los principales creadores de empleo, ya que es responsable del $13,5 \%$ de los puestos de trabajo.

${ }^{3}$ La fuerte actividad de los últimos años no es suficiente justificación, ya que, por ejemplo Irlanda ha contado con una vitalidad equivalente.

${ }^{4}$ Habrá que esperar, además, a los nuevos planes de inversión pública, que se pondrán en funcionamiento en el segundo semestre y que contribuirán, sin duda, a dinamizar el proceso de generación de empleo en el sector, a corto plazo para la construcción de las infraestructuras, y a largo plazo para las labores de conservación y mantenimiento. 


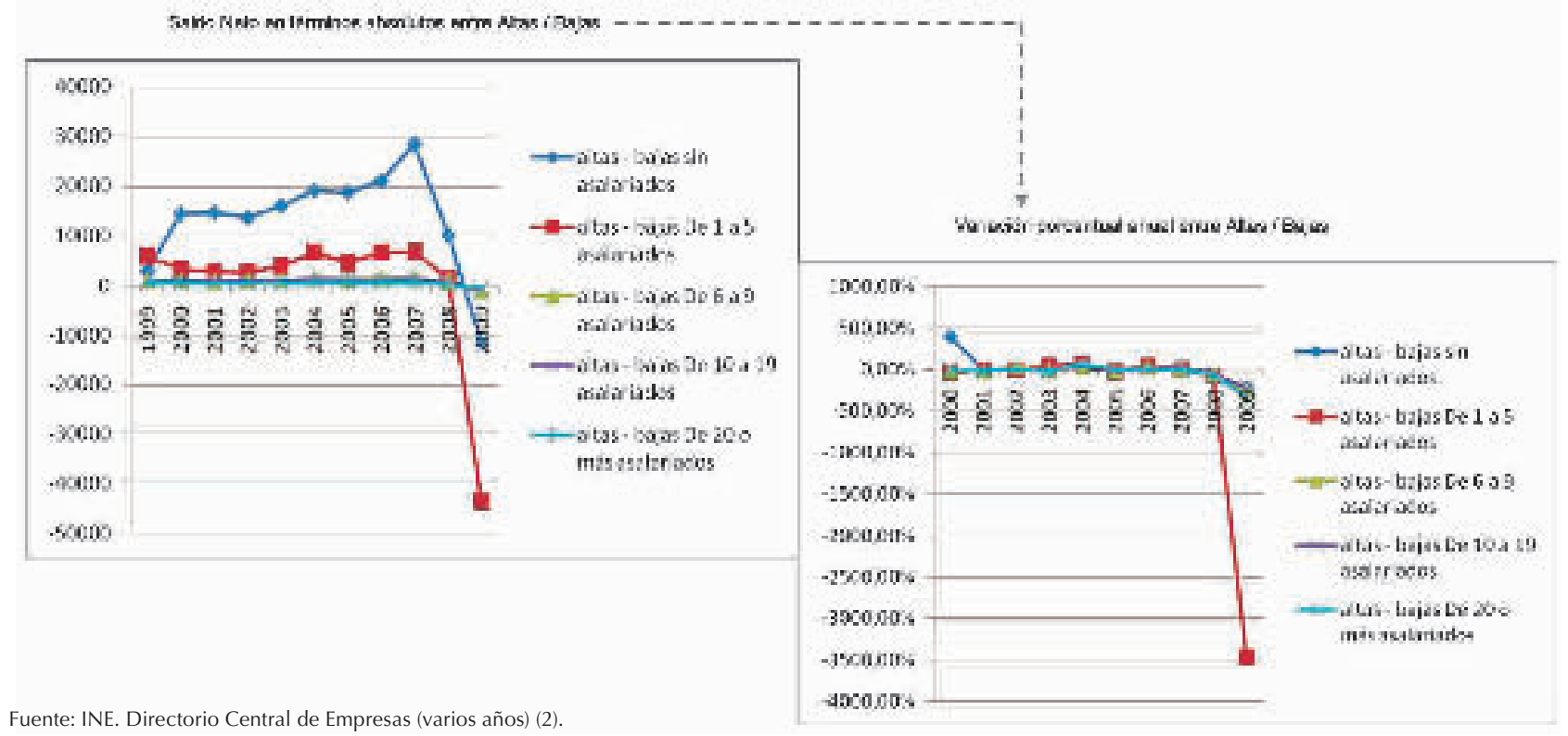

la figura 3, que muestra el saldo y la variación de la diferencia entre altas y bajas de compañías del sector. El impacto en los movimientos poblacionales del sector se prevé incluso superior al registrado con la anterior información, dado que la fecha de referencia para este indicador es el 1 de enero.

Para un análisis más detallado desagregaremos el sector en torno a la naturaleza de los trabajos.

\subsection{Obra Civil}

La Federación de la Industria Europea de la Construcción (FIEC) reconoce la necesidad de iniciativas a largo plazo encaminadas a la creación de un marco robusto de obra civil para contribuir al desarrollo sostenible -en términos económicos, sociales y medioambientales- de modo que sea capaz de responder a las necesidades de las generaciones futuras (véase figura 4).

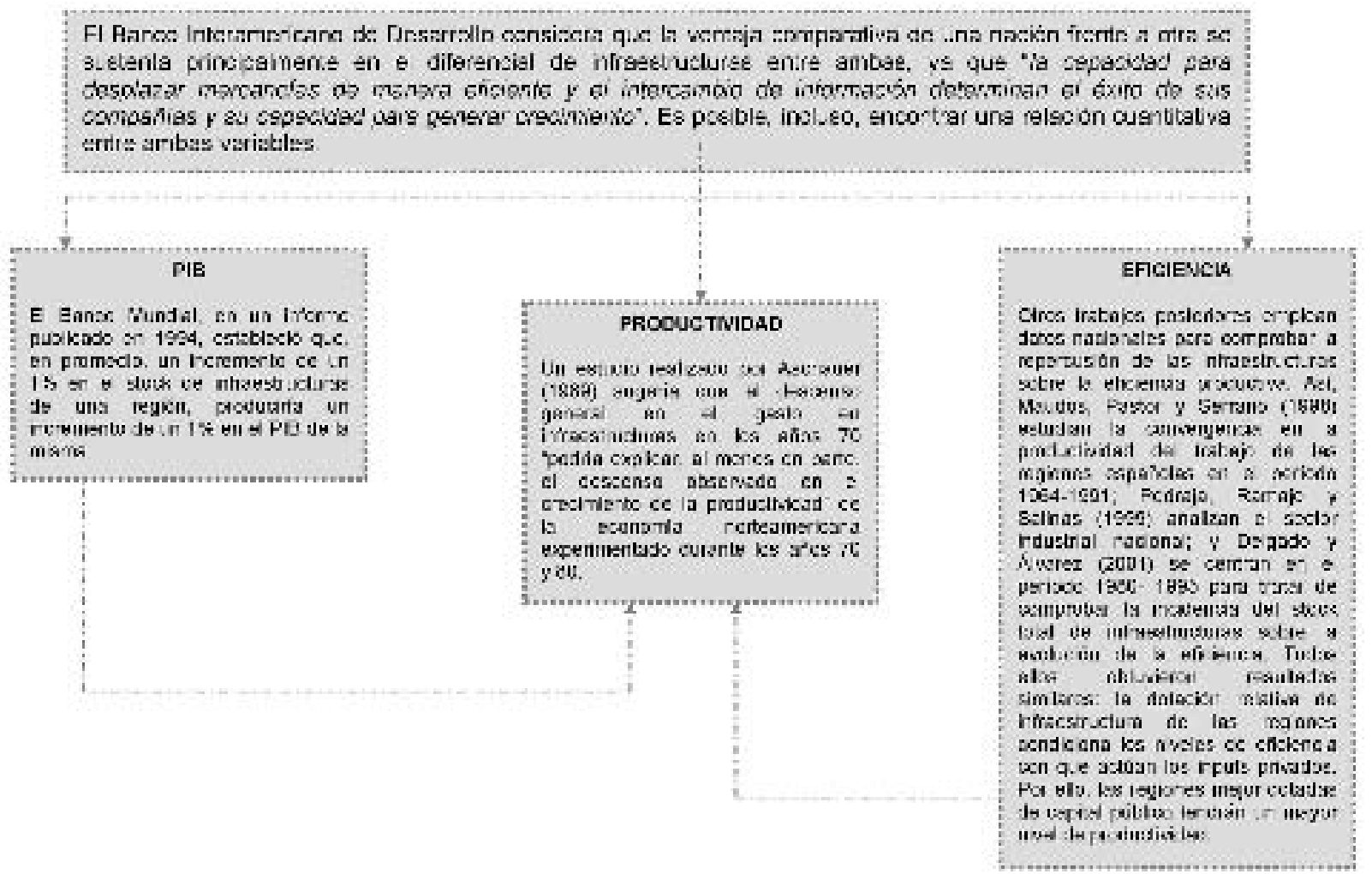


El marco necesario en materia de infraestructuras debe recoger tanto medidas legislativas que incorporen mecanismos e instrumentos adaptados y flexibles, como programas de impulso directo. La necesidad de reducir el déficit impuesto por los criterios de convergencia europea y la búsqueda de mayores cotas de eficiencia han llevado a los poderes públicos a recurrir a la financiación y gestión privada de los mismos. La consecuencia directa de esta transformación es el traslado de las cargas de construcción y explotación de las infraestructuras a los usuarios, y no sólo la ejecución, sino también la gestión y el mantenimiento por parte de empresas privadas. Más aún: los recursos privados son la solución para el problema de la escasez de fondos de las instituciones para el desarrollo de infraestructuras, ya sean de transporte (carreteras, ferrocarril, metro, etc.), hospitales, centros educativos, prisiones, o bien, oficinas públicas en general, aunque éste no es un procedimiento novedoso en Europa. La utilización de capital privado para desarrollar proyectos públicos se ha empleado desde el siglo XIX en muchos países y es un mecanismo intensificado por las nuevas necesidades de infraestructuras.

Sin embargo, el significado de esta colaboración público-privada varía en función de la interpretación que se haga de los conceptos de "financiación privada" y de riesgo, lo que determinará las funciones de las empresas involucradas, su grado de responsabilidad $y$, en consecuencia, el perfil rentabilidadriesgo de estas operaciones.
Siguiendo a Ruiz Ojeda (8), existen dos respuestas a este problema: para la tradición anglosajona, la financiación privada supone la asignación de riesgos a las empresas involucradas; mientras que para la tradición europeo-continental, supone "la delegación de funciones públicas en una instancia no inserta orgánicamente en el bloque institucional de la Administración". Ambos enfoques se enfrentan hoy a una misma realidad: recursos públicos limitados y necesidad de fuertes inversiones para mantener la competitividad de las regiones, en un entorno integrado, en el que las políticas comunes abarcan cada vez un ámbito mayor. Por tanto, desde la Unión Europea deben tenerse en cuenta las particularidades económicas, financieras, contables y las relacionadas con la transferencia de riesgos de todas las legislaciones nacionales si quieren conseguirse progresos en las materias consideradas clave: la creación de un Mercado único real, el apoyo a las Pymes, el desarrollo de la colaboración público-privada entre las autoridades locales y otras entidades y, en resumen, el éxito de la estrategia de crecimiento de la Unión. La Comisión Europea presentó en 2004 el Libro Verde sobre la Colaboración Público Privada y el derecho comunitario en materia de contratación pública y concesiones, con el que se pretende englobar la pluralidad de criterios de las distintas regulaciones e impulsar una práctica muy ventajosa. Del modelo de la Colaboración Público Privada (CPP), muy apropiado en la actualidad para los países comunitarios, debemos considerar tanto las Medidas Legislativas como los Programas de Inversión Directa (véase figura 5).
5. Obra Civil en España: Medidas egislativas y Programa de Inversión Directa (PEIT).

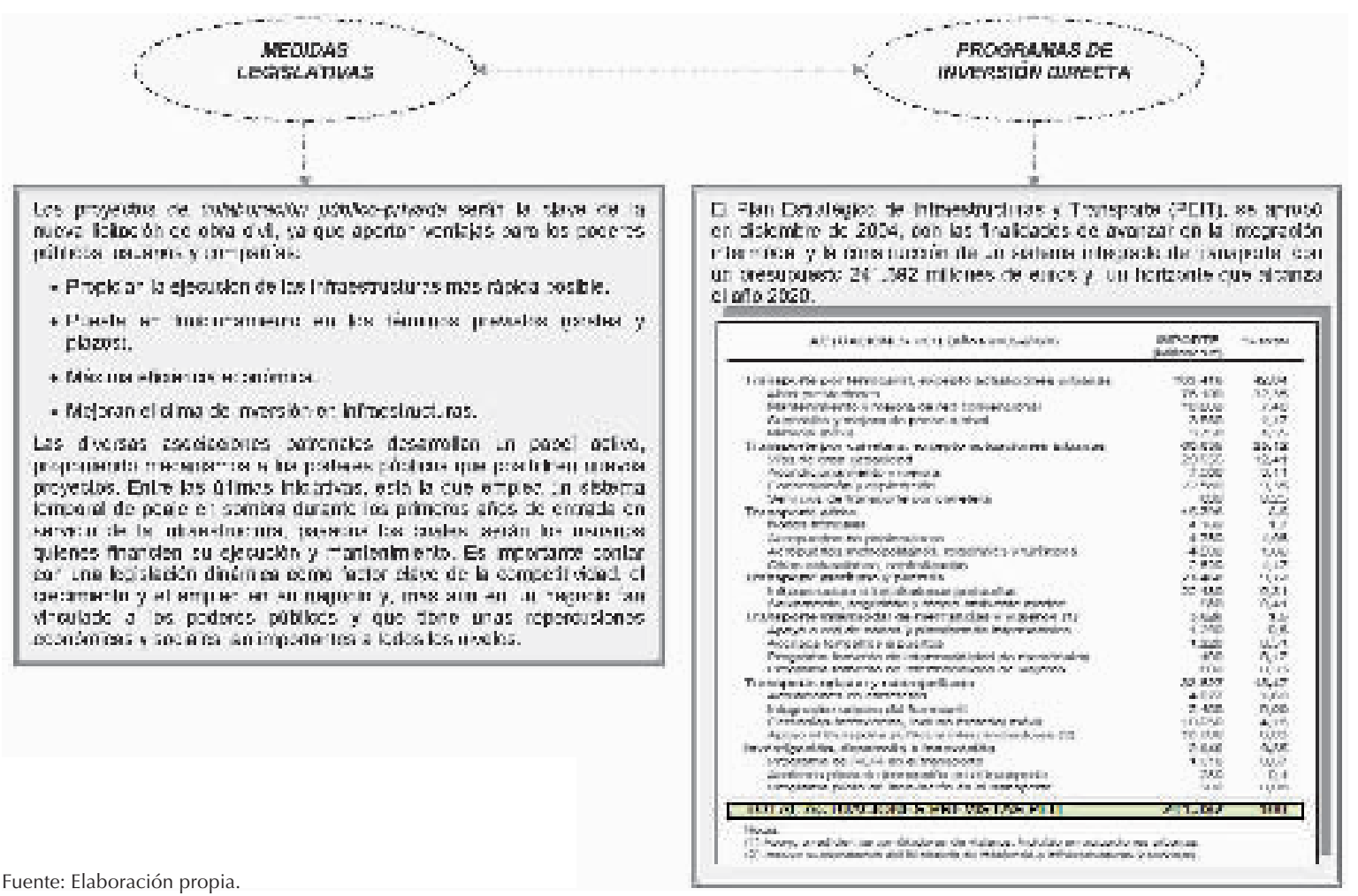




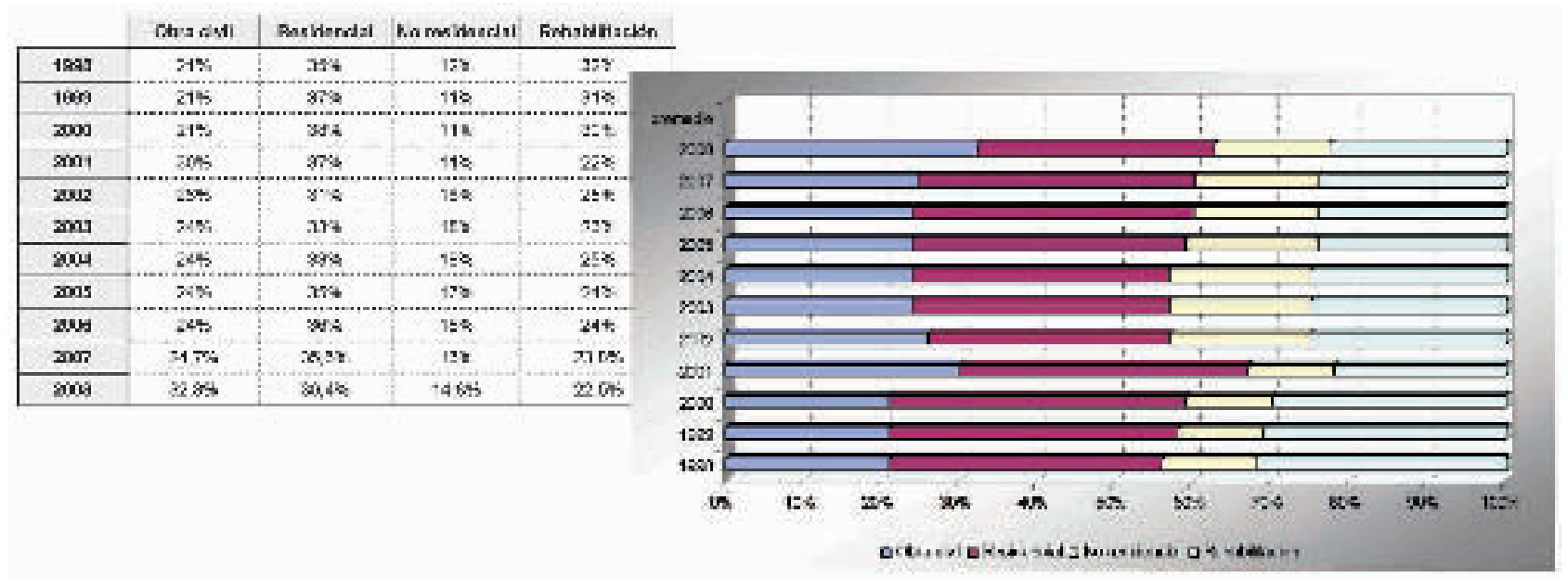

Fuente: Elaboración propia a partir de datos de SEOPAN (varios años) (1).

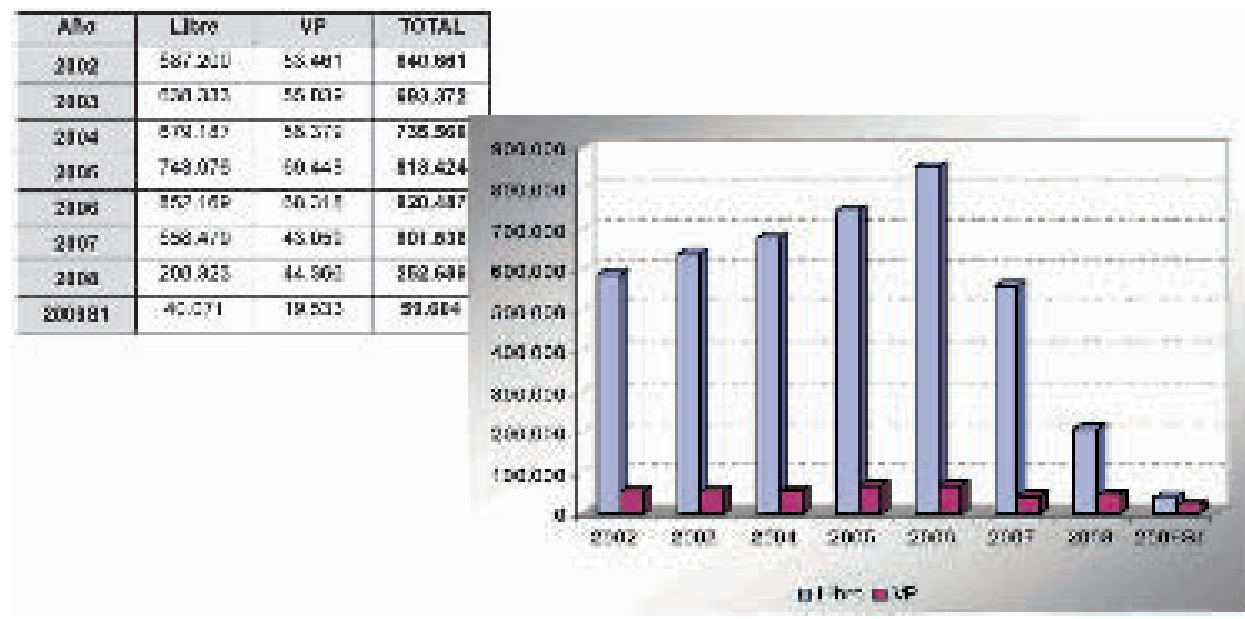

Fuente: CSCAE (9).

6. Importancia relativa de los subsectores de la construcción en España (1998-2008).

7. Número de visados de obra (2002-2009).
${ }^{5}$ El Observatorio de la Vivienda, por su parte, manifiesta que, hasta ahora, cualquier ayuda que ha ido al precio de la adquisición ha sido absorbida por el precio del suelo.

\subsection{Edificación}

La edificación constituye el $75 \%$ de la actividad, como resultado de agregar las actividades de creación de nuevos inmuebles y rehabilitación de los existentes, cualesquiera que sean sus características y finalidad (véase figura 6).

Durante los últimos años, los márgenes de la construcción se han ido recortando progresivamente, hasta situarse, según fuentes del sector en casi un tercio de lo que suponía a mediados de los años 80. Dado que los precios de los diferentes inputs del proceso de construcción (materiales y mano de obra) han experimentado subidas muy inferiores a las del precio final de las construcciones, el margen generado en el precio se ha desviado a la retribución del suelo. Resulta ya generalmente aceptado que la subida del precio de los inmuebles produce dos efectos: la subida del precio del suelo y el aumento de los márgenes del promotor. Se abando- nó la idea de que fue la escasez de suelo la responsable de las subidas del precio de la vivienda; más aún, cuando se hizo patente una expansión de suelo edificable superior a las necesidades de edificación, en términos de demanda final, incluso en momentos en que el nivel constructivo se situó en máximos históricos ${ }^{5}$ (en 2006 se iniciaron más de 900.000 viviendas) (véase figura 7).

Por lo tanto, no fue la construcción la que absorbió los importantes aumentos de precios, sino la promoción y los propietarios de suelo, que se beneficiaron de un nivel de demanda inusualmente alto, principalmente por la facilidad de acceso al crédito y unos tipos de interés menores que el nivel medio a largo plazo. Sin embargo, las constructoras sí se beneficiaron de un período largo de fuerte actividad. Por tanto, para estas compañías, lo relevante en el entorno es la fortaleza de la demanda, e internamente, la estructura financiera y la toma de decisiones estratégicas, para acceder a mercados o actividades con menor compo- 
nente cíclico. Desde el estallido del mercado de vivienda en 2007, se han visto gravemente perjudicadas, ya que, en estas situaciones, los potenciales compradores retrasan sus operaciones a la espera de condiciones más favorables. De hecho, desde entonces, la demanda ha caído a niveles desconocidos, alcanzando en el primer trimestre de 2009, tan sólo el $41,6 \%$ del máximo trimestral de transacciones registrado en el segundo trimestre de 2006 (véase figura 8). Los nuevos requisitos del Código Técnico de la Edificación mejoran las características de los inmuebles y exigen la actualización de la formación del personal, la incorporación de materiales con mayor valor añadido -por ejemplo, los requisitos en temas de acústica y eficiencia energética- y nuevos procedimientos de montaje, aunque no repercuten en el recorte de márgenes de las constructoras, ya que estos costes serán repercutidos al comprador.

Es importante no infravalorar la importancia de las actividades de rehabilitación y man- tenimiento, que constituyen el $24 \%$ de los trabajos del sector y que aumentará considerablemente, ante el fuerte incremento del stock de inmuebles generado durante los últimos años. Estas actividades, que suponen el $36 \%$ del sector en la UE, son un impulso para la actividad en épocas de retroceso de la cifra de nuevas promociones, convirtiéndose en una de las direcciones hacia las que tenderemos a medio plazo.

\section{ESTRUCTURA DE LA INDUSTRIA DE LA CONSTRUCCIÓN EN ESPAÑ̃}

La construcción es una industria muy fragmentada, por razones geográficas, la naturaleza del trabajo y las características de las propias empresas. Los datos del DIRCE (2), estructurados en base a la Clasificación CNAE indican que, en 2009, existen 217.539 empresas y 224.417 profesionales que trabajan por cuenta propia cuya actividad principal es la construcción (véase tabla 1).

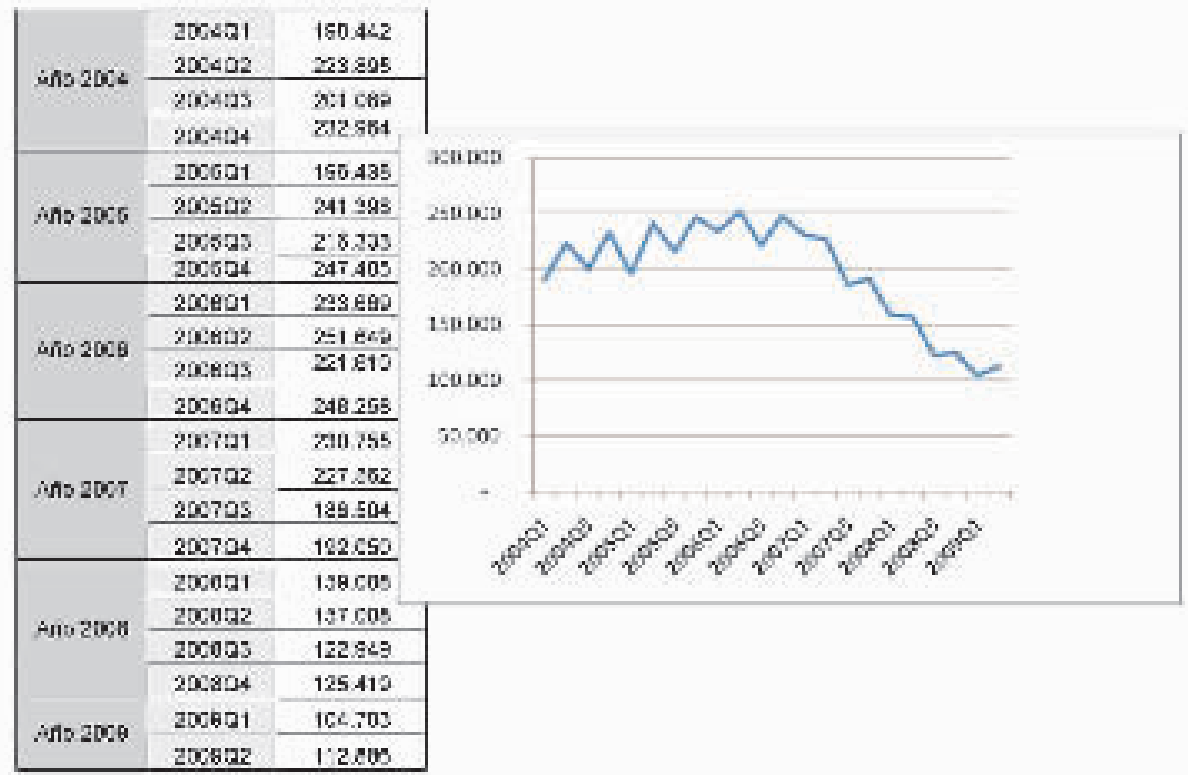

Fuente: Elaboración propia a partir de datos del Ministerio de Vivienda

Tabla 1

Las empresas constructoras en España. Número de empresas

\begin{tabular}{|l|r|r|r|r|}
\cline { 2 - 5 } \multicolumn{1}{c|}{} & $\mathbf{1 9 9 9}$ & $\mathbf{2 0 0 7}$ & $\mathbf{2 0 0 8}$ & $\mathbf{2 0 0 9}$ \\
\hline Mas de 1.000 asalariados & 24 & 41 & 48 & 4 \\
\hline de 500 a 999 asalariados & 28 & 87 & 91 & 58 \\
\hline de 200 a 499 asalariados & 194 & 481 & 559 & 246 \\
\hline de 100 a 199 asalariados & 582 & 1.222 & 1.283 & 1.046 \\
\hline de 50 a 99 asalariados & 1.684 & 3.081 & 2.974 & 2.264 \\
\hline hasta 49 asalariados & 144.782 & 255.322 & 262.624 & 213.885 \\
\hline sin asalariados & 124.322 & 228.174 & 233.477 & 224.417 \\
\hline TOTAL & 271.616 & 488.408 & 501.056 & 441.956 \\
\hline
\end{tabular}

Fuente: INE. Directorio Central de Empresas (varios años) (2). 
${ }^{6}$ Éste es el caso de la construcción, en el que el 46,19\% de la población corresponde a negocios sin asalariados y el $37,77 \%$ corresponde a empresas que cuentan con un máximo de 5 empleados.

7 Partiendo de la clasificación de Fomento de la Producción, que elabora un sector compuesto por constructoras e inmobiliarias, se han eliminado aquellas compañías que no realizan la ejecución de los proyectos (las inmobiliarias puras o inmobiliarias no integradas verticalmente "hacia atrás").

${ }^{8} \mathrm{CRk}$ (índices discretos): ratios de concentración puramente dichos, representan la suma de la cuota de mercado de las k empresas más grandes.

$$
C R_{k}=\sum_{i=1}^{k} s_{i}
$$

Siendo, si la cuota de mercado de la empresa i.

El índice de Rosenbluth (R), con interpretación geométrica en términos de curva de concentración.

$$
R=\frac{1}{2 \sum_{i=1}^{n} i \cdot S_{i}-1}
$$

Familia de índices de HannahKay: tienen en cuenta toda la curva de concentración y no únicamente un punto, como ocurre con los ratios de concentración. La expresión general de esta familia de índices es:

$$
H K(a)=\sum_{i=1}^{n}\left[S_{i}^{a}\right]^{\frac{1}{a-1}}
$$

Siendo a cualquier número real mayor que 0 . Los más utilizados son aquéllos en que $\mathrm{a}=1$ (índice de entropía) y $\mathrm{a}=2$ (índice de Herfindahl).

El índice de Gini: mide el grado en que una distribución de recursos se desvía con respecto a la igualdad perfecta. Se calcula como la superficie entre la curva de Lorenz y la recta de equidistribución. Cuanto mayor sea el área entre ambas, mayores serán la
Se pone de manifiesto, por tanto, cómo todo tipo de empresa tiene cabida en el negocio, aunque la asignación de los proyectos se realiza en base a las variables consideradas críticas: el tamaño y la especialización, siendo ambas independientes entre sí, ya que, además de las grandes, también las pequeñas y medianas pueden participar en trabajos de gran complejidad y especialización. Sin embargo, estas compañías no pueden realizar por sí mismas proyectos de gran tamaño.

Por tanto, la variable tamaño es la que aporta el mayor factor discriminante para definir las características de cada grupo de compañías y de la propia industria. Para ello, la referencia será el número de empleados, ya que las distintas estrategias en relación a la composición del balance y las prácticas realizadas durante el proceso de producción hacen que las otras medidas (cifras de activo y de facturación) no sean tan representativas como aquella.

Cuando se estudia la rentabilidad y la creación de valor a nivel de industria, se cuenta con el inconveniente de la agregación de datos no siempre homogéneos, como consecuencia de las características de la población empresarial. Por este motivo, una parte considerable de su actividad no aparece en las estadísticas, dificultando la comparación de los ratios de actividad y ocasionando resultados engañosos ${ }^{6}$. Debido a esta problemática, estos índices de concentración tienen una validez limitada cuando se refieren a una industria tan fragmentada, dispersa y heterogénea. En este tipo de industrias, además, es frecuente encontrar distintas pautas de evolución en función de las características de las empresas y de sus mercados. En esto, la construcción no es una excepción. Durante los últimos años se están produciendo dos fenómenos opuestos:

- En el segmento de las más grandes compañías, importantes fusiones e integraciones de empresas, acarrearon un fuerte incremento en la concentración de esta parte de la oferta.

- En el segmento de las compañías más pequeñas (microempresas), el momento expansivo de la industria en los seis primeros años de década provocó la aparición de múltiples pequeñas nuevas compañías, especialmente de menos de 6 asalariados. Posteriormente, desde 2007, la tasa de nuevas altas de compañías se redujo drásticamente, aumentando vertiginosamente la tasa de bajas de constructoras, especialmente, las menores de 6 trabajadores, pero en todos los intervalos.

Se hace patente, por tanto, la mayor volatilidad de las empresas más pequeñas dado que los datos ofrecidos por las empresas sin asalariados tienen importantes dificultades de tratamiento por razón de su reducida transparencia. Del mismo modo, se constata la vulnerabilidad de las empresas de más de 20 asalariados, que no se encuentran en la cúspide de la industria, al depender de las empresas más grandes para su supervivencia (por medio, sobre todo, de contratos subordinados o alianzas estratégicas).

Los datos disponibles hacen patente el fuerte incremento en el número de pequeñas constructoras y, dado que los índices de concentración se basan en dos variables: el número de elementos y su tamaño relativo, esto tiene un doble efecto. Por un lado, provoca que la fuerte concentración experimentada por el segmento de mayores compañías, vía integración, no sea apreciable -si se emplean exclusivamente estos indicadores-; y por otro, provoca que, en la parte descendente del ciclo, los indicadores sobrerreaccionen, experimentando un fuerte incremento de concentración, debido, fundamentalmente a razones de tipo financiero y a la desaparición de aquellas empresas menos competitivas.

Esto motiva el interés en conocer qué es lo que está ocurriendo en el segmento de referencia, el compuesto por las mayores compañías. Para ello, emplearemos la publicación y base de datos de Fomento de la Producción, que elabora anualmente un ranking de las mayores empresas de cada sector ${ }^{7}$.

\subsection{Concentración de las 50 Mayores Empresas. Evolución Histórica}

Los índices de concentración de la industria resumen, en un único estadístico, cuál es la estructura de la misma, atendiendo al número de empresas y a su tamaño relativo. Son muchos los indicadores de concentración que se emplean en la literatura económica y facilitan distintos enfoques e interpretaciones.

El resultado de aplicar los más extendidos ${ }^{8}$ al segmento de las 50 mayores constructoras se recoge en las tablas 2 y 3 , de las que pueden extraerse las siguientes conclusiones:

1. La concentración de la industria es mayor en términos de plantilla de trabajadores que en términos de facturación. A pesar de que las grandes empresas no ejecutan los trabajos por si mismas, la entrada en otros negocios menos cíclicos y que proporcionan ingresos recurrentes las ha llevado a aumentar el número de trabajadores propios.

2. El incremento de concentración se produce con mayor intensidad en términos de facturación, debido a la introducción 
Tabla 2

Índices de concentración de TOP50 constructoras. Facturación

\begin{tabular}{|l|r|r|r|r|}
\cline { 2 - 5 } \multicolumn{1}{c|}{} & \multicolumn{1}{|c|}{$\mathbf{1 9 9 9}$} & $\mathbf{2 0 0 7}$ & $\mathbf{2 0 0 8}$ & \multicolumn{1}{c|}{$\mathbf{2 0 0 9}$} \\
\hline Mas de 1.000 asalariados & 24 & 41 & 48 & 4 \\
\hline de 500 a 999 asalariados & 28 & 87 & 91 & 58 \\
\hline de 200 a 499 asalariados & 194 & 481 & 559 & 246 \\
\hline de 100 a 199 asalariados & 582 & 1.222 & 1.283 & 1.046 \\
\hline de 50 a 99 asalariados & 1.684 & 3.081 & 2.974 & 2.264 \\
\hline hasta 49 asalariados & 144.782 & 255.322 & 262.624 & 213.885 \\
\hline sin asalariados & 124.322 & 228.174 & 233.477 & 224.417 \\
\hline TOTAL & 271.616 & 488.408 & 501.056 & 441.956 \\
\hline
\end{tabular}

Fuente: INE. Directorio Central de Empresas (varios años) (2).

Tabla 3

Índices de concentración de TOP50 constructoras. Plantilla

\begin{tabular}{|l|c|c|c|c|c|c|c|c|c|c|}
\cline { 2 - 11 } \multicolumn{1}{c|}{} & $\mathbf{1 9 9 3}$ & $\mathbf{1 9 9 5}$ & $\mathbf{2 0 0 0}$ & $\mathbf{2 0 0 1}$ & $\mathbf{2 0 0 2}$ & $\mathbf{2 0 0 3}$ & $\mathbf{2 0 0 4}$ & $\mathbf{2 0 0 5}$ & $\mathbf{2 0 0 6}$ & $\mathbf{2 0 0 7}$ \\
\hline CR1 & $15,15 \%$ & $16,53 \%$ & $16,32 \%$ & $16,23 \%$ & $16,07 \%$ & $21,82 \%$ & $23,87 \%$ & $22,66 \%$ & $25,50 \%$ & $20,72 \%$ \\
\hline CR5 & $50,76 \%$ & $56,15 \%$ & $68,12 \%$ & $67,39 \%$ & $69,33 \%$ & $69,47 \%$ & $70,27 \%$ & $69,62 \%$ & $75,25 \%$ & $72,61 \%$ \\
\hline CR10 & $69,86 \%$ & $72,88 \%$ & $83,10 \%$ & $82,78 \%$ & $83,56 \%$ & $82,10 \%$ & $82,10 \%$ & $80,73 \%$ & $83,51 \%$ & $83,24 \%$ \\
\hline R & 0,054 & 0,058 & 0,077 & 0,076 & 0,075 & 0,077 & 0,076 & 0,074 & 0,074 & 0,074 \\
\hline HK1 (entropía) & 3,161 & 3,051 & 2,747 & 2,771 & 2,743 & 2,723 & 2,702 & 2,732 & 2,533 & 2,616 \\
\hline HK2 (IHH) & 0,068 & 0,082 & 0,102 & 0,101 & 0,105 & 0,113 & 0,120 & 0,116 & 0,146 & 0,131 \\
\hline G & 0,617 & 0,643 & 0,720 & 0,715 & 0,712 & 0,757 & 0,723 & 0,714 & 0,743 & 0,732 \\
\hline Y & 86,203 & 92,909 & 143,672 & 138,535 & 132,134 & 133,526 & 135,167 & 634,362 & 677,395 & 664,566 \\
\hline
\end{tabular}

Fuente: Elaboración propia a partir de la base de datos de Fomento de la Producción (11).

de trabajos de terceros en los proyectos propios.

3. Todos los índices (y no sólo los ratios discretos (CR)) reflejan el aumento de la concentración en épocas de fuerte actividad (exceptuando la varianza de los logaritmos de las cuotas de mercado (v), en la que se observa mayor variabilidad, debido a su propia definición, pues prima la importancia de las pequeñas empresas frente a las que tienen mayor cuota). Posteriormente, la concentración muestra visos de retroceso, debido a que el crecimiento se extiende a todos los actores del mercado, tanto en términos de facturación, como de plantilla.

4. Las compañías toman como referencia a quienes las anteceden en el ranking y observan y replican a éstas dentro de sus posibilidades. En este sentido podemos identificar los siguientes comportamientos:

a. El crecimiento es tanto más intenso cuanto mayores son los agentes. El músculo financiero con que cuentan las empresas más potentes hace que puedan desarrollar su ideal de crecimiento con más intensidad que el resto, como así se produce y se manifiesta en que las 5 mayores empresas hayan crecido desde 2001 hasta 2007 un $150 \%$ en facturación y un $107 \%$ en número de empleados, mientras que la facturación de toda la muestra ha aumentado el $132 \%$ y el número de empleados el 98,5\%.

b. Puede identificarse cierto retardo entre el comportamiento de grandes y no tan grandes. En la apertura de línea estratégica, las mayores compañías aumentan las diferencias con el resto. Lo mismo ocurre en las primeras etapas de la fase alcista. Cuando los seguidores comienzan a copiar, las diferencias se reducen y llegan a un mínimo cuando las grandes han estabilizado su conducta y las pequeñas siguen actuando en el mismo sentido, hasta que las mayores inician otra línea de actuación.

Cuando comienza el retroceso cíclico, clásico en el sector, las empresas más vulnerables son las primeras en experimentar el retroceso, es decir, las más pequeñas y las más endeudadas ${ }^{9}$.

c. Los valores absolutos de las magnitudes muestran cómo las iniciativas de las grandes son seguidas por el resto, produciendo un "efecto elástico".

5. Parece clara la existencia de líderes estratégicos, ya que se observa el mencionado "efecto elástico", tanto en facturación, como en plantilla, puesto que el despegue del TOP es seguido por los agentes próximos $^{10}$. desigualdad de la distribución y el valor del índice.

$$
G=\frac{\sum\left|p_{i}-q_{i}\right|}{\sum p_{i}}
$$

Siendo: si la cuota de mercado de la empresa i. $p_{i}$ el porcentaje que suponen las i compañías de menor facturación. qi el porcentaje agregado de facturación que suponen las i empresas de menor facturación:

$$
q_{i}=\frac{s_{1}+s_{2}+s_{3}+\ldots+s_{i}}{s_{1}+s_{2}+s_{3}+\ldots+s_{n}}
$$

La varianza de los logaritmos de las cuotas de mercado: es una medida exacta del grado de desigualdad en los casos en que la industria está formada por numerosas empresas pequeñas y medianas y pocas empresas grandes (las empresas se distribuyen siguiendo una función logarítmica normal).

$$
v=\sum_{i=1}^{N}\left(\ln S_{i}-\ln \bar{S}\right)^{2}
$$

${ }^{9}$ En este punto, se plantea una posible línea de trabajo, incrementando la segmentación del grupo, empleando criterios estratégicos y determinar hasta qué punto puede demostrarse la existencia de líderes estratégicos. En su caso, se abre la línea para describir, en base a criterios cuantitativos, los parámetros que determinan la posición en el esquema leaderfollower.

${ }^{10}$ Deberá analizarse el comportamiento estratégico por segmentos para determinar si existe una conducta líderseguidor con significatividad estadística en el sector. 


\subsection{Empresas Referente}

La repercusión de la actividad y la estrategia de las grandes empresas se pone de manifiesto en el resto de constructoras, pero también en la economía nacional, e incluso, en sectores completos de otras economías extranjeras.

Estas empresas son los líderes estratégicos y el punto de referencia de la industria de construcción y están mostrando una fuerte influencia en muchos aspectos, entre los que podemos destacar los siguientes:

- Están transformando el producto inmobiliario, al promover grandes complejos de viviendas que incorporan locales comerciales e instalaciones de ocio y entretenimiento.

- Tienen un tamaño y eficiencia que les permite acceder no sólo a economías emergentes, sino a países desarrollados, como los de Europa occidental y a Estados Unidos, donde situaron uno de los focos estratégico de su crecimiento vía adquisiciones.

- Son capaces de influir en los mercados de los países donde tienen su foco estratégico. Por ejemplo, el desembarco de las filiales de promoción de estos grupos (así como del resto de inmobiliarias) en el centro y este de Europa revolucionó sus mercados residenciales.

- Son creadores de nuevos focos de demanda, ya que el precio de estos nuevos inmuebles hace que sólo los inversores de la Europa Occidental tengan potencial comprador para los productos, desplazando, en muchos casos, la demanda interna. Lo sucedido en Polonia es uno de los ejemplos más claros. Los precios de su mercado residencial se triplicaron entre 2001 y 2005. Lo mismo ocurre con las superficies comerciales, otro producto en el que nuestras constructoras e inmobiliarias mostraron gran interés, adquiriendo masivamente edificios emblemáticos en el centro de las grandes capitales de diversos países. Con el descalabro del mercado inmobiliario mundial, las empresas que se embarcaron en estos proyectos, tuvieron que replantear sus estrategias.

${ }^{11}$ Además, destaca que, en la posición número 11 , se encuentra Hochtief, grupo alemán controlado por ACS.
- Tienen una influencia continua y permanente en otros sectores. Han demostrado tener la llave de entrada en compañías que, por motivos económicos y sociales, presentan un alto valor estratégico, como fueron primero las telecomunicaciones, consolidándose, posteriormente, en concesiones y servicios públicos y, más tarde, en energía.

- Son protagonistas de excepción en la transformación del mercado de concesiones mundial y del mercado energético europeo, tanto por la vía del proceso de integración empresarial como por el propio desarrollo de su actividad como operadores globales.

Durante los últimos años, las grandes constructoras españolas han servido de referencia para el resto de compañías del sector. Han marcado las líneas de actuación del negocio, han experimentado un fuerte crecimiento y se han posicionado con mucha fuerza en los mercados internacionales. En los últimos veinte años, la cifra de facturación internacional de las empresas constructoras se ha multiplicado por 13 y hay signos claros de que esta predominancia se mantendrá en el futuro, ya que la nueva contratación se mantendrá fuerte en los próximos años, garantizada por los fondos de la UE y el hecho de que nuestras empresas son competitivas en los mercados internacionales.

Según Public Works Financing, en 2009, 7 de los 10 mayores concesionarios de infraestructuras del mundo por número de operaciones eran compañías españolas (ACS, Itínere (Sacyr), Cintra (Ferrovial), Global Vía (FCC y Caja Madrid), Abertis y OHL y Acciona $)^{11}$, con presencia en Alemania, Andorra, Argentina, Australia, Bélgica, Brasil, Canadá, Chile, China, Colombia, Costa Rica, Ecuador, España, Estados Unidos, Francia, Irlanda, Israel, Jamaica, México, Panamá, Portugal, Puerto Rico, Reino Unido, República Dominicana, Sudáfrica y Suiza, especializadas en carreteras y ferrocarriles, aunque con una importancia creciente en proyectos relacionados con la captación, desalación y tratamiento de aguas (mediante contratos de construcción, administración y gestión de las infraestructuras).

\section{ESTRUCTURA DE LOS COSTES. LA SUBCONTRATACIÓN}

El dinamismo del entorno hace que la flexibilidad sea un instrumento clave para el éxito de toda estrategia, lo que lleva a las empresas a centrarse en sus competencias básicas y a externalizar las partes que con- 
sideran complementarias del proceso productivo $^{12}$

La utilización generalizada de la subcontratación modifica así la estructura, la actividad productiva y las relaciones que mantienen unas empresas con otras, transformando el panorama empresarial en su conjunto $^{13}$.

Por su parte, las instituciones públicas también ponen de manifiesto que la subcontratación es un factor "cada vez más importante en la competitividad de las empresas", ya que ofrece oportunidades para agentes especializados y favorece el crecimiento de pequeñas y medianas empresas ${ }^{14}$. Pese a no estar orientado de forma específica a la construcción, estas iniciativas pueden servir de guía para el sector de la construcción, en la situación actual en que las compañías españolas están orientadas a su proyección internacional y la importancia de los contratos con clientes de la UE en sus carteras de negocios.

González, Arruñada y Fernández (15), en su estudio sobre la construcción, observan cómo la subcontratación se reduce a medida que los trabajos desarrollados son más específicos y cómo aumenta ante posibles problemas de control interno, causados por la variedad de los trabajos y la dispersión geográfica de las actividades.

Son varios los motivos que llevan a las empresas a subcontratar parte de los trabajos en los proyectos de que son responsables. Tanto en edificación como en obra civil, puede darse el caso de compañías que se encuentran capacitadas para la ejecución completa de los trabajos pero que renuncian a una cartera más reducida de proyectos en los que son responsables únicos a cambio de incrementar el número de obras en que participan, compartiendo beneficios y responsabilidad. Ésta es una forma de centrarse en aquello que las compañías consideran sus capacidades distintivas e introduciendo a otras para que se encarguen del resto de competencias.

En el caso de la obra civil, la complejidad de los proyectos lleva a los adjudicatarios a acudir a especialistas que, a su vez, en muchos casos subcontratan parte de su trabajo a otras aún más especializadas. Son habituales las cadenas de subcontrataciones, en las que los subcontratistas del proyecto principal se posicionan, a su vez, como contratistas principales de subcontratas subordinadas a la parte del proyecto de la que son

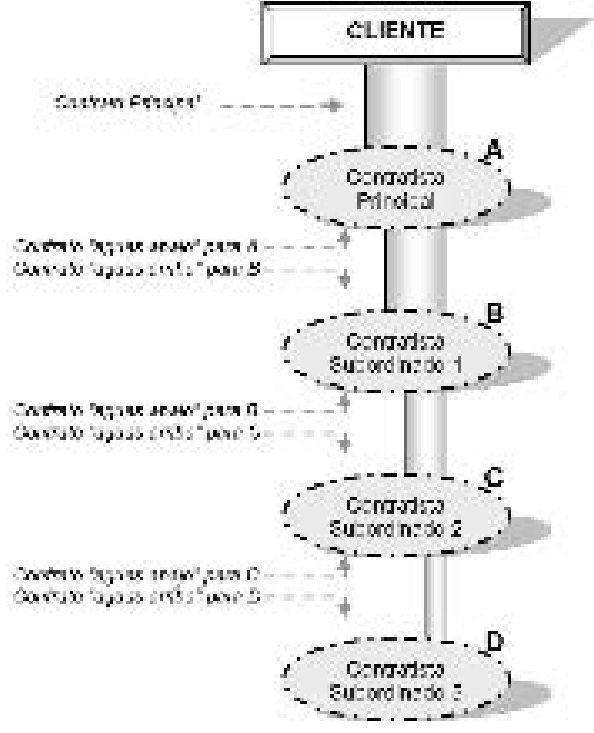

Fuente: Elaboración propia.

responsables. Éste es el motivo por el que las Administraciones deben regular las condiciones de la cadena de subcontrataciones en aquellos contratos que licita de forma pública.

Con frecuencia, aunque exista un único adjudicatario principal de las obras, es un grupo de empresas el que se encarga de la realización de los trabajos (ver figura 9). A este respecto, los subcontratistas quedaran obligados sólo ante el contratista principal y será éste quien deberá asumir la total responsabilidad de la ejecución del contrato frente a la Administración, con arreglo estricto a los pliegos de cláusulas administrativas particulares y a los términos del contrato. La subcontratación es, además, una práctica en expansión. Su utilización se ha incrementado de forma continua durante los últimos 25 años y supone en la actualidad el 38,2\% de los trabajos, más del doble que en 1988. Pero su empleo no es homogéneo en todos los proyectos, sino que es más frecuente en la obra civil (en la que el $40 \%$ de la actividad se subcontrata), con una tendencia creciente para la que aún no se vislumbra máximo.

Las estadísticas que hacen referencia al sector, publicadas por el Ministerio de Fomento, ponen de manifiesto que el tamaño de la empresa, además de ser una variable decisiva en la definición del binomio actividad-mercado, también influye en la combinación de recursos empleada para conseguir el producto final.

Los motivos que han provocado la sustitución de los recursos productivos propios por los partenariados empresariales tienen su
9. Cadena de subcontratación.

${ }^{12}$ Grossman y Helpman (13), teniendo en cuenta el trade-off que existe entre los costes de optar por una forma de organización más grande y menos especializada y los costes de transacción basados en la búsqueda y los contratos imperfectos, construyen un modelo en el que la subcontratación y la integración vertical se tratan como fenómenos de equilibrio (considerando la interdependencia en las decisiones).

${ }^{13}$ Es la causa, según Sabel (14) de una estructura productiva descentralizada, ya que conduce a la creación de redes de proveedores y subcontratistas que funcionan como instrumentos de cooperación entre las empresas y que refuerzan los vínculos con los mercados internacionales y con otros sectores.

${ }^{14}$ Para el Consejo Europeo, el mercado único es la mejor forma de garantizar el empleo sistemático de la subcontratación transnacional en el marco de utilización creciente de recursos externos. La Comisión Europea, por su parte, reconoce que la colaboración entre empresas produce efectos en términos de ahorro en tiempo, ahorro en gastos generales y recursos destinados a I+D, la mejora en la calidad de los productos y la mayor homogeneidad de los mismos. Es por ello que desarrolla iniciativas para solucionar problemas concretos y fomentar la cooperación interempresarial. 


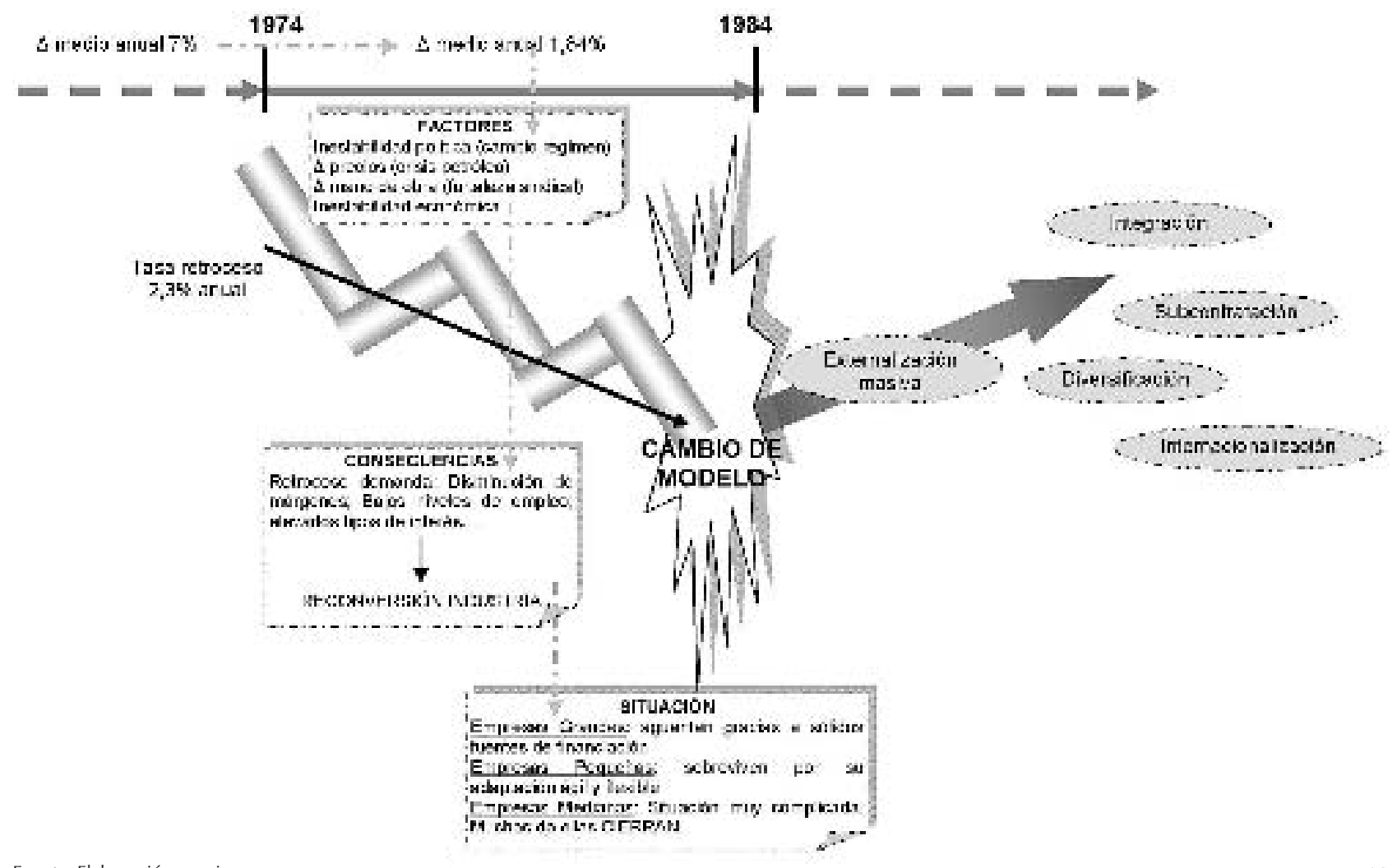

Fuente: Elaboración propia.

10. La transformación de la industria de la construcción. Análisis cronológico. base en la crisis de la construcción de los años 80, que hizo que las grandes compañías se deshicieran de una parte importante de sus inmovilizados y modificaran su actitud ante los proyectos (véase figura 10).

Pasaron entonces de realizar las obras con medios propios, a convertirse en gestores de proyectos y ensambladores de los trabajos subcontratados, aprovechando su conocimiento del negocio de las grandes obras civiles y sus características diferenciales: tamaño, capacitación técnica y solvente estructura financiera.

A corto plazo, si las constructoras y, en especial, las más grandes, redujeran su tendencia a la subcontratación, se observaría una mejora en sus ratios actuales de productividad de los consumos intermedios, lo que supondría sustituir unos recursos por otros con mayor productividad, mejorando así la productividad global y, en definitiva, su margen operativo. Sin embargo, como dice Mouritsen (16), "el precio de la flexibilidad se paga en términos de productividad". Y por eso, en una industria tan cíclica y tan ligada a decisiones políticas -que son, en definitiva, las que determinan los mecanismos y el nivel de inversión en infraestructurasel interés consiste en asegurar un volumen suficiente de actividad para el mayor plazo posible, manteniendo la capacidad de hacer frente a la parte negativa del ciclo sin asumir los costes de una gran estructura inactiva y complementando su cartera de negocios con actividades de menor componente cíclico, como son los servicios.

Y éste es el principal objetivo de todas las constructoras: conseguir la máxima flexibilidad de su estructura, desarrollando una política de total subcontratación de los trabajos y limitando su papel al ensamblaje de los trabajos externalizados y a la gestión técnica de grandes proyectos. Sin embargo, no todas las empresas tienen la capacitación técnica necesaria para realizar la gestión de proyectos de gran envergadura, para lo que resulta fundamental el tamaño y la experiencia acumulada. Por lo tanto, cuantos más trabajos de esta naturaleza se hayan realizado y mayor sea la cartera de proyectos en curso, mayor capacidad de negociación tendrá la empresa y mayores las posibilidades de ser elegida como adjudicataria.

Muy pocas empresas reúnen estas características, lo que hace que sólo una pequeña proporción de las compañías tenga vocación de contratista principal de grandes proyectos. El resto debe adoptar otra estrategia.

Unas pocas se centrarán en edificación o, en general, en proyectos de menor envergadura -que, salvo casos concretos, no exigen estrictos requisitos, más allá de asequibles niveles técnicos y la necesaria eficiencia en la gestión que le permita ofrecer precios competitivos- que pueden realizar por completo con sus medios o con un recurso 
complementario a la subcontratación. El resto deberá actuar habitualmente como subcontratista, aunque tratando de condicionar este papel a la existencia de compromisos de actividad a largo plazo.

\section{EL ENRIQUECIMIENTO DE LA CARTERA DE NEGOCIOS DE LAS CONSTRUCTORAS ESPAÑOLAS}

La mayoría de decisiones estratégicas de las empresas que persiguen mantener su liderazgo están orientadas a la creación de valor empresarial, y la toma de decisiones estratégicas forma parte de un proceso organizativo que está claramente condicionado por las características organizativas y humanas de cada compañía. Siguiendo a Andrews (17), "la estrategia corporativa es el modelo de decisiones de una empresa que determina y manifiesta sus objetivos, fines o metas, que genera las normas de actuación y los planes para lograr los objetivos y que determina la variedad de negocios a los que se dedicará, el tipo de organización económica y humana que es o trata de ser y el carácter de la contribución económica y no económica que pretende hacer para sus accionistas, empleados, clientes y sociedad en general".

Los Consejos de Administración de las constructoras deben delimitar, por tanto, estrategias a largo plazo que permitan estabilizar cuentas de resultados muy cíclicas, si se atiende a la actividad originaria de estas empresas, gestionando grupos inmersos en una actividad que genera mucho cash-flow con la rentabilidad de un mercado maduro, en torno al 3\%. Lo que han hecho estas dos últimas décadas ha sido invertir todo ese efectivo en negocios más lucrativos, cambiando radicalmente el panorama de la industria. Las principales empresas constructoras hoy son el resultado de continuas operaciones de integración sucesivas desde comienzos de los noventa. De hecho, las seis compañías cotizadas en 2009, eran 23 empresas independientes dos décadas atrás, con trayectorias muy diferentes. En este tiempo, se han fusionado, integrado, han tomado el control de sus rivales y también de compañías que poco tenían que ver con su actividad y han salido al mercado internacional (véase tabla 4).

Tabla 4

Integración constructoras españolas desde 1990.

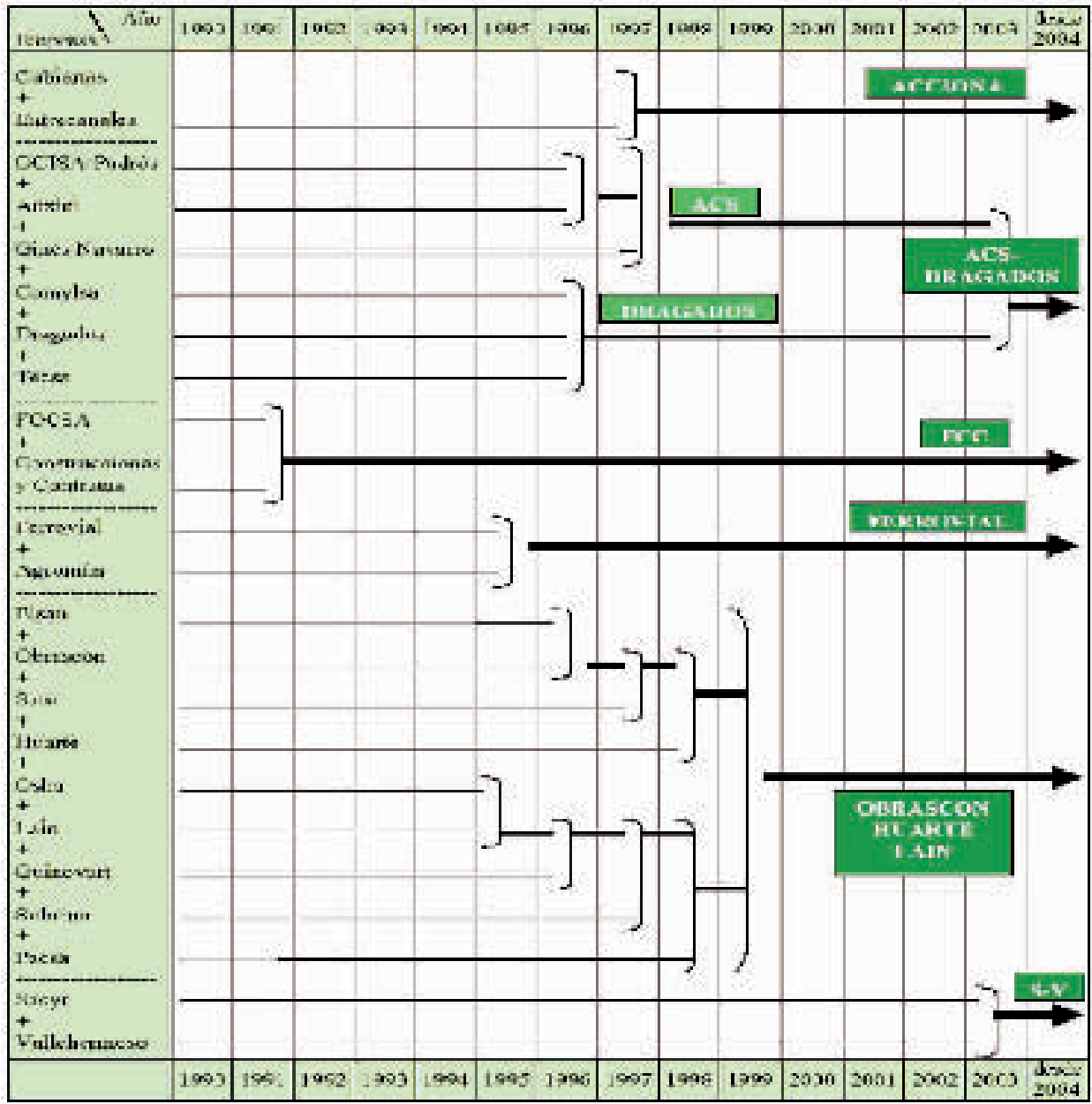

Fuente: Elaboración propia. 


\subsection{Integración Vertical de la Empresa Edificadora}

La integración vertical fue el primer paso en el enriquecimiento del objeto social de las constructoras y les permitió aprovechar las oportunidades de un mercado que conocían y que ofrecía la posibilidad de fuertes retornos, convirtiéndose en sus propios clientes. En la industria de la construcción, aunque es posible la integración hacia delante y hacia atrás, es mucho más frecuente la primera de ellas. El negocio inmobiliario constituye el primer paso en el proceso de diversificación para las constructoras. Sin embargo, las actividades inmobiliarias son muy diversas y no todas plantean el mismo interés, al menos a priori, a las constructoras con intención de aumentar el ámbito de sus negocios.

Dicho de otro modo, el sector inmobiliario se enfoca a la promoción, la explotación económica de inmuebles y las actividades relacionadas con su gestión y administración. El Libro Blanco del Sector Inmobiliario distingue únicamente dos subsectores: promoción inmobiliaria y explotación de bienes inmuebles, como base de dos tipos de productos: inmuebles nuevos para venta e inmuebles en renta.

En lo que se refiere al primero, las compañías constructoras conocen tanto las características de los proyectos como sus necesidades financieras y de otro tipo, debido a que intervienen de forma directa en su ejecución. Dado que el proceso completo del bien inmobiliario consta de tres fases: gestión, construcción y comercialización, para que la constructora pueda absorber los márgenes del promotor, sólo tiene que integrar las funciones de gestión y comercialización. La primera de ellas no incorpora dificultades añadidas, ya que su actividad tradicional le aporta el conocimiento sobre las necesidades del proyecto en cada momento. En cuanto a la comercialización, tampoco supone un incremento significativo de complejidad, ya que el mercado de inmuebles es transparente y los precios y condiciones de las transmisiones son conocidas. La estructura de la competencia es similar en la promoción y la construcción y la dificultad radica en el aumento de la estructura de la compañía y la financiación necesaria para abordar los proyectos. Esto tampoco constituye un obstáculo, dado que la financiación de proyectos inmobiliarios puede realizarse con un alto nivel de apalancamiento, gracias a las garantías hipotecarias o pignoraticias, aunque es sensible al endurecimiento de las condiciones crediticias.

En cuanto al segundo, las constructoras pueden plantear un paso más en la integración vertical hacia delante, explotando los inmuebles que promueven y construyen. Para ello, el principal obstáculo sería la fuerte inmovilización de recursos necesaria para desempeñar esta última actividad. Una opción estratégica elegida por grandes empresas es la especialización en segmentos de negocio en los que se elimina la interferencia de pequeños competidores, por medio de la explotación de inmuebles en las zonas más selectas, lo que dificulta, por su coste de entrada, la participación de las compañías con menor capacidad financiera.

Hasta 2005, muchas constructoras invirtieron los fuertes beneficios de la parte alta del ciclo del sector en estas actividades. Desde esta fecha, la evolución del sector inmobiliario, con estrategias muy agresivas de crecimiento e internacionalización, con el fin de incorporar las carteras de suelo e inmuebles, y la fuerte concentración empresarial, produjo el abandono, parcial o total, del negocio inmobiliario por parte de grupos no puramente inmobiliarios, justo antes del fuerte deterioro de las perspectivas relativas el mercado de la vivienda, por el ajuste en el sector, en precios y demanda, ocasionando el fuerte crecimiento de la aversión al riesgo relativo.

Este paso fue primordial para las constructoras, porque les permitió un fuerte crecimiento, en una actividad con importantes retornos, al tiempo que les permitía conseguir la masa crítica para acometer proyectos más ambiciosos y, en muchos, casos, conseguir jugosas plusvalías con la desinversión en estos activos en momentos de sobrecalentamiento en los mercados.

El maduro mercado español de la construcción propició el lanzamiento hacia otras actividades y áreas geográficas, en un contexto de nulas restricciones crediticias y dinero barato, en un paso más hacia la conformación de operadores globales de construcción, servicios (y, en algunos casos, energía).

\subsection{Diversificación e Internacionalización}

Es indudable que las grandes constructoras españolas han ampliado su marco de actuación a nuevas actividades y áreas geográficas. Sin embargo, no existe un indicador universal capaz de determinar de manera inequívoca cuándo una empresa está más diversificada que otra, si ambas cuentan con carteras formadas por múltiples actividades y en las que cada una tiene un peso relativo diferente.

Los indicadores más representativos de diversificación e internacionalización (Her- 
findahl, Entropía y el índice de especialización)-, por su construcción, pueden no reflejar la magnitud real de la transformación experimentada en la industria, ya que hay componentes subjetivos que dificultan la comparación entre empresas, e incluso, en la propia serie histórica de una misma empresa para un plazo de observación prolongado. Sin embargo, es evidente que las constructoras españolas, durante los últimos 15 años, han aumentado considerablemente su ámbito de actividad.

Las constructoras deben aprovechar su bagaje como gestores y no olvidar el resultado que sus predecesores han tenido en experiencias similares. La decisión acerca de la idoneidad de las estrategias basadas en la diversificación para hacer frente a las características del entorno no es nueva en el ámbito empresarial y académico y, cincuenta años después de que se abriese el debate por primera vez, no existe consenso sobre la mayor o menor adecuación de las estrategias de concentración o diversificación, aunque a lo largo del tiempo la postura predominante ha cambiado en función de sus resultados.

En todo caso, los resultados que han logrado nuestras grandes constructoras durante los últimos años, ponen de manifiesto que la diversificación industrial repercute de forma clara en su rentabilidad. Esto es razonable porque otros negocios distintos de la construcción, como pueden ser los servicios, son muy estables y aún están asociados a mayores márgenes.

Otras actividades maduras, como la energía, aportan estabilidad y tasas elevadas de rentabilidad vía dividendo.

La internacionalización tiene una menor repercusión en la rentabilidad, dado que las empresas que compiten en los mercados internacionales cuentan con la competencia de los operadores locales, que conocen mejor las características de sus mercados y, también, la de los grupos globales, dotados de gran eficiencia. Por lo tanto, la actividad internacional proporciona la oportunidad de participar en grandes proyectos, en muchos casos, con el apoyo de especialistas o empresas locales, que enriquecen el bagaje de los participantes y aportan la experiencia necesaria para futuras licitaciones.

Sin embargo, como contrapartida, habitualmente tienen un porcentaje de rentabilidad menor (en términos absolutos pueden proporcionar elevados beneficios) y pueden incrementar el nivel de riesgo global de la compañía.

\section{CONCLUSIONES}

En la construcción conviven empresas de características muy dispares: un número elevado de Pymes y trabajadores por cuenta propia, con un pequeño número de grandes compañías cuyo mercado de referencia es el nacional. Las más grandes son operadores internacionales y cuentan con un objeto social muy diversificado. Cada segmento de tamaño se centra en contratos con unas condiciones determinadas, en términos de naturaleza y ámbito geográfico, aunque existen especialistas cuya actividad poco tiene que ver con la pauta general del segmento a que pertenecen. Los líderes de la industria utilizan su dimensión y sus características diferenciales respecto de otras más pequeñas como instrumentos competitivos:

- Están dotadas de una gestión profesionalizada de máximo nivel que les está permitiendo aprovechar su potencial operativo, financiero y estratégico, en un sector en el que, tradicionalmente, los propietarios de las empresas contaban con reducida formación y fuerte capacidad de negociación.

- Cuentan con niveles formativos elevados y un papel diferente en el proceso productivo, especialmente en trabajos de gran volumen y complejidad.

- Usan intensivamente los contratos subordinados en las obras, lo que proporciona capacidad para intervenir en un volumen de proyectos muy superior y de elevada flexibilidad, restando vulnerabilidad ante la parte baja del ciclo.

- Se han convertido en gestores de proyectos, en los catalizadores que hacen que se unan eficaz y eficientemente las contribuciones de múltiples especialistas que actúan como responsables de partes concretas de los trabajos.

- En general, tanto la obra civil como la edificación son negocios maduros, con fuerte competencia en todo el territorio nacional, lo que, sumado a las necesidades de crecimiento de estas empresas, las ha empujado a lanzarse a los proyectos internacionales de infraestructuras y a la actividad conjunta de promociónconstrucción en mercados con más recorrido.

- El foco de la estrategia de estas empresas está en la diversificación industrial (entrada en negocios diferentes de los relacionados con la construcción) y la diversificación geográfica o internacionalización. 
Las constructoras medianas toman como referencia a las grandes empresas y desarrollan dos iniciativas estratégicas:

- Configuran una cartera de negocios en base a las estrategias que han mostrado ser efectivas en el segmento inmediatamente superior, introduciendo la integración vertical y la diversificación como instrumentos de defensa ante la previsible contracción del mercado.

- Dado que no pueden emplear el tamaño como instrumento competitivo, deberán especializarse en los trabajos que forman parte de su objeto social.

- Cada vez es menor la proporción de contratos en su cartera vinculados al procedimiento ejecución de obras-emisión de certificaciones-cobro, ya que las nuevas modalidades de contratos con la Administración a que, de forma individual o consorciada, tienen acceso estas compañías, modifican este esquema tradicional, con la retribución mediante la explotación de instalaciones anexas o el pago aplazado.

- La nueva situación se caracteriza por el menor volumen (en términos relativos) de recursos financieros procedentes de la explotación (acreedores comerciales), la sustitución por recursos financieros no relacionados con la explotación (especialmente bancarios) y una mayor importancia de capitales permanentes que favorecen una gestión más a largo plazo de los fondos.

La gestión financiera ha experimentado en las empresas constructoras una profunda transformación. El fuerte descenso de los tipos de interés ha reducido el beneficio que les suponía la financiación con cargo a proveedores como elemento generador de valor. El endeudamiento se ha convertido en la clave del crecimiento $y$, durante años, el sector financiero no ha establecido límites para la financiación de proyectos de expansión, geográfica e industrial, siempre que estas empresas pudiesen acreditar una trayectoria probada y la viabilidad de las operaciones basada en sus fundamentales. El "credit crunch" de 2008 dejó el sistema sin recursos financieros y comprometió, no sólo la política de crecimiento de las compañías, sino también la operativa diaria. Cada vez más, las variables financieras son clave en la estrategia de las compañías, destacando entre todas ellas el nivel de endeudamiento, así que debe analizarse las operaciones para poder acceder a nuevo endeudamiento a tipos de interés accesibles.
En cuanto a las perspectivas de la industria en relación con la externalización de contratos, los últimos cambios regulatorios pueden calificarse de conservadores, ya que no modifican sustancialmente las condiciones de contratación. La actividad vinculada a contratos privados ha experimentado, tan sólo, leves alteraciones.

En la industria de la construcción se producen cadenas de subcontrataciones inusualmente largas $y$, muchas veces, sin una justificación por razones de especialización o cualificación profesional, lo que perjudica la seguridad de los trabajadores (es el sector con mayor grado de accidentalidad) y la calidad de los servicios prestados, que realizan las obras, desembocando en unos márgenes prácticamente inexistentes en los últimos eslabones de la cadena. Estas largas cadenas de subcontratas no proporcionan, por tanto, las ventajas con que fueron concebidas. La última modificación legislativa aprobada -la Ley 32/2006, de 18 de octubre, reguladora de la subcontratación en el Sector de la Construcción- se ha preparado con un enfoque estrictamente sectorial, buscando un marco de especialización de compañías y trabajadores, que fomente la inversión en nueva tecnología y que, en definitiva, mejore la eficiencia empresarial, fijando garantías que eviten "situaciones objetivas de riesgo para la seguridad y salud de los trabajadores $^{\prime \prime 15}$.

En resumen: la situación actual y la nueva normativa apuntan hacia un entorno en el que las constructoras no necesitan prepararse ante inminentes cambios en esta materia. La regulación seguirá favoreciendo a grandes operadores y las reformas solicitadas por las empresas medianas durante los últimos tiempos, tales como la reforma del tratamiento de las ofertas anormalmente bajas y la reconsideración de los criterios de adjudicación -evaluando exclusivamente las ofertas presentadas, de forma que no se prime a ningún operador-deberán seguir esperando.

Por todo ello, la estrategia de las constructoras no debe modificarse sustancialmente: aquellas que puedan utilizar el tamaño para competir, deben seguir haciéndolo, mientras que el resto debe especializarse como medida de diferenciación.

La clave para una buena salud en el sector, ante la fuerte desaceleración en la rama residencial, será la obra civil. Se debe impulsar un marco dinámico de contratación, especialmente bajo la colaboración públicoprivada. De hecho, en abril de 2010, se ha aprobado un Plan Extraordinario de Colaboración Público-Privada, que moviliza una 
inversión por valor de 17.000 millones de euros, equivalente al 1,7\% del PIB, para la segunda mitad de 2010 y 2011, que recurre al modelo concesional y que transfiere al concesionario los riesgos de construcción y de disponibilidad.

Hasta ahora se consideraba más apropiado para las asociaciones público-privadas, el concurso, porque permite conseguir el "mejor valor", es decir, las mejores condiciones globales dentro del grupo de ofertas, en lugar de atender únicamente al precio (como ocurre en la subasta).

Actualmente se está potenciando el diálogo competitivo, como complemento al concurso y existen modelos mixtos que pueden aportar un dinamismo a la situación actual:

- Alianzas público-privadas, en las que los socios de ambas categorías participan conjuntamente en el diseño, desarrollo, construcción y financiación de los proyectos, así como su gestión y mantenimiento en condiciones de funcionamiento.

- Agrupación de proyectos, de forma que se sacan a licitación grupos de pequeños proyectos, con el fin de reducir el conjunto de procesos de contratación y de reducir los costes globales de transacción.

- Asociaciones competitivas, en las que se seleccionan varios socios privados en competencia, con el fin de repartir las partes de un proyecto. Este tipo de asociaciones pueden ser dinámicas, de forma que el socio público puede reasignar las partes del proyecto en función del desempeño.

- Asociaciones incrementales, en las que el socio público contrata con un socio privado partes concretas de proyectos, que pueden ser suspendidas o incrementadas en función del desempeño del agente privado. También existe la posibilidad de recurrir a nuevos socios, cuando sea necesario.

- El integrador, que es el socio privado responsable de gestionar el proyecto y de repartir las funciones y actividades de terceros. Como responsable de la coordinación, obtiene retribución/sanción en función del éxito, los retrasos, sobrecostes y/o defectos de calidad.

Para resolver el problema de la inversión en proyectos menos rentables desde el punto de vista económico (explotación concesional), se estudian nuevos modelos de financiación mixta: los peajes blandos o los sistemas temporales de peaje en sombra durante los primeros años de entrada en servicio de la infraestructura, en los que el sector público apoyaría la realización de la infraestructura durante un periodo limitado de tiempo y del resto se encargaría la concesionaria.

La importancia de participar activamente en los contratos licitados actualmente en obra civil y en servicios públicos se basa en el prolongado periodo temporal que proporcionarán facturación y rentabilidad a los adjudicatarios, pero también se debe a que configurarán la base del conocimiento necesario para conseguir contratos a medio o largo plazo en el negocio. La generalización de contratos que incorporan ejecución, explotación y mantenimiento hace que los candidatos deban reducir drásticamente sus márgenes si quieren actuar como contratistas principales, o de lo contrario, deberán convertirse en subcontratistas, con menores márgenes durante décadas. Y aún no es posible conocer el volumen de contratación ni los mecanismos vigentes en ese momento, por lo que la apuesta de las empresas constructoras debe ser fuerte y decidida y definirá qué quiere ser cada una y cómo quiere serlo de ahora en adelante.

\section{BIBLIOGRAFÍA}

(1) SEOPAN (2003, 2004, 2005, 2006, 2007, 2008, 2009): Informe sobre la construcción. SEOPAN, Madrid.

(2) Directorio Central de Empresas (varios años): http://www.ine.es/jaxi/menu.do?type=pcaxis\&path= $\% 2 \mathrm{Ft} 37 / \mathrm{p} 201 \&$ file $=$ inebase $\& \mathrm{~L}=0$

(3) Banco Mundial: "Valuing Infrastructure Stocks and Gains from Improved Performance", working paper, 1994.

(4) Aschauer, D.: "Is public expenditure productive?" Journal of Monetary Economics, 23, pp. 177200, 1989.

(5) Maudos, J.; Pastor, J. M.; Serrano, L.: "Convergencia en las regiones españolas: cambio técnico, eficiencia y productividad". Revista Española de Economía, Vol. 15, n² 2, pp. 235-264, 1998. 
(6) Pedraja, F.; Ramajo, J.; Salinas, J.: "Eficiencia productiva del sector industrial español: un análisis espacial y sectorial", Papeles de Economía Española, no 80, pp. 51-67, 1999.

(7) Delgado Rodríguez, M. J.; Álvarez Ayuso, I.: "Medición de la eficiencia técnica en la economía española: el papel de las infraestructuras productivas", Papeles de trabajo del Instituto de Estudios Fiscales. Serie económica 18/2001, 2001.

(8) Ruiz Ojeda, A.: "Dominio público y financiación privada de infraestructuras y equipamientos. Un estudio del caso francés y análisis comparativo de la reciente regulación española". Ed. Marcial Pons, 1999.

(9) Consejo Superior de Arquitectos de España (CSCAE): www.cscae.com

(10) Ministerio de Vivienda: www.mviv.es

(11) Fomento de la Producción: http://www.fomenweb.com:80/

(12) Public Works Financing: http://www.pwfinance.net/

(13) Grossman, G. M.; Helpman, E.: "Integration versus Outsourcing in Industry Equilibrium", The Quarterly Journal of Economics, pp. 85-120, 2002.

(14) Sabel, C.: "Flexible Specialization and the Re-emergence of Regional Economies", Reversing Industrial Decline, P. Hirst y J. Zeitlin (eds.), Oxford: Berg, 1988.

(15) González, M.; Arruñada, B.; Fernández, A.: "La decisión de subcontratar: el caso de las empresas constructoras". Investigaciones Económicas. Vol. XXI (3), pp. 501-521, 1997.

(16) Mouritsen, J.: "The flexible firm: strategies for a subcontractor's management control". Accounting, Organizations and Society. Vol. I, n 24, enero 1999, pp 31-55, 1999.

(17) Andrews, K.: "The concept of corporate strategy". Irwin, 1980; citado en Mintzberg, H.; Quinn, J. B.; Goshal, S.: "El proceso estratégico". Edición europea revisada. Prentice Hall, 1998. 